\title{
Pancreatic Neuroendocrine Tumors Are Characterized by Loss of Noxa Expression that Can be Recovered by the Proteasome Inhibitor Bortezomib
}

\author{
E. P. Slater, J. Waldmann, C. López, E. Matthäi, V. Fendrich, D. K. Bartsch
}

Department of Surgery, Philipps University, Marburg, Germany.

Email: slater@med.uni-marburg.de

Received August $2^{\text {nd }}, 2013$; revised September $2^{\text {nd }}, 2013$; accepted September $10^{\text {th }}, 2013$

Copyright (C) 2013 E. P. Slater et al. This is an open access article distributed under the Creative Commons Attribution License, which permits unrestricted use, distribution, and reproduction in any medium, provided the original work is properly cited.

\begin{abstract}
Prognosis in well-differentiated neuroendocrine carcinomas varies considerably and therapeutic targets for metastatic disease are urgently needed. cDNA microarray studies in our laboratory revealed a significantly lower expression level of the Noxa-gene in human pancreatic neuroendocrine neoplasms (PNENs) as compared to normal islet cells. To determine the validity of the downregulation of Noxa in PNENs, benign and malignant tumors from both sporadic and MEN1 patients were selected for expression analysis. To further verify the findings, neuroendocrine BON1 and QGP cell lines were tested for Noxa expression and its recovery by treatment with the proteasome inhibitor bortezomib. The expression of Noxa was significantly downregulated in 20 PNENs ( $\mathrm{p}=0.0036)$. There was no significant difference between MEN1 and sporadic tumors. However, the malignant tumors showed a more significant decrease as compared to benign tumors $(\mathrm{p}=0.0385)$ and the decrease in expression in tumors greater than $20 \mathrm{~mm}$ was very highly significant ( $\mathrm{p}<0.0001)$. Neither the BON1 nor QGP1 cell lines displayed expression of Noxa protein in the absence of the proteasome inhibitor, Bortezomib. After stimulation with the drug for $16 \mathrm{~h}$, the expression was induced in both cell lines that are correlated with an increase in the level of c-MYC expression, cleaved caspase 3 and cell death. The low expression level of Noxa in PNENs contributes to the inability of these tumor entities to undergo apoptosis. The recovery of Noxa expression following treatment with the proteasome inhibitor, bortezomib, leading to caspase activation and cell death supports the use of such drugs for the treatment of these tumor entities.
\end{abstract}

Keywords: Pancreatic Neuroendocrine Neoplasms; Noxa, Bortezomib

\section{Introduction}

Pancreatic neuroendocrine neoplasms (PNENs) represent $5 \%-10 \%$ of pancreatic tumors and include gastrinoma, insulinoma and non-functioning endocrine tumors. They occur sporadically or in the autosomal dominant inherited syndromes such as multiple endocrine neoplasia type 1 (MEN1) and von-Hippel-Lindau. Although plasma chromogranin A and 24-h urine for 5-hydroxyindole acetic acid are known prognostic markers for survival in patients with such tumors, the role of other tumor markers is not well described [1,2]. Although these tumors are surgically manageable, metastatic disease is present in $\sim 50 \%$ of patients at the time of diagnosis, and the overall 5 -year survival for patients with distant metastasis is only $22 \%$. Somatostatin analogues, IFN- $\alpha$ or hepatic artery chemoembolization provide good palliation of the symp- toms of carcinoid syndrome associated with such tumors. However, few systemic therapies have been shown to consistently elicit tumor responses and prolong survival. Recently, the mTor-inhibitor, everolimus, and the multitargeting sunitinib have been shown to increase overall survival in randomized controlled trials $[3,4]$. The ineffectiveness of most systemic chemotherapy in metastatic neuroendocrine tumors may relate to their unique biological features such as slow growth pattern or hypervascularity [5].

The p53 tumor-suppressor protein functions as a transcriptional activator and several p53-inducible genes that play a role in the induction of apoptosis in response to p53 have been described [6]. The pro-apoptotic gene, Noxa encodes a Bcl-2 homology 3 (BH3)-only member of the Bcl-2 family of proteins that inactivates the pro- 
tective function of the pro-survival members of the Bcl-2 family and unleashes the mitochondrial-based apoptotic cascade by activating the Bax/Bak-like pro-apoptotic family members. In fact treatment of metastatic melanoma or multiple myeloma with proteasome inhibitors has been reported to result in selective tumor cell killing by triggering the induction of Noxa expression [7,8].

A cDNA microarray analysis with 11,500 genes was performed using RNA from 10 gastrinoma tumor samples, both sporadic and MEN1, and compared to RNA from normal islet cells obtained from healthy donors as reference. The comparative analysis of gene expression patterns revealed overexpression of 15 and underexpression of 123 genes greater than 3 -fold [9]. Included in this list was the gene Noxa, a proapoptotic member of the Bcl-2 family [10]. We hypothesized that this loss could contribute to tumor progression and proceeded to analyze the expression in a wider range of PNENs to verify these results and correlate them with clinical findings.

\section{Materials and Methods}

\subsection{Patients}

We randomly selected 10 patients with benign and 10 patients with malignant neuroendocrine pancreatic tumors from the tumor bank at our institute. Five of each group were genetically confirmed MEN1 patients. Clinical data were prospectively recorded and analyzed with special regard to symptoms. The diagnosis of a functional tumor was established if hormone excess was present, excluding an isolated elevation of pancreatic polypeptide (PP). Zollinger-Ellison Syndrome (ZES) was diagnosed in the presence of clinical symptoms, an elevated fasting serum gastrin level (ref $<125 \mathrm{pg} / \mathrm{ml}$ ), a positive secretin stimulation test (increase $>200 \mathrm{pg} / \mathrm{ml}$ ) and a low $\mathrm{pH}$ of the stomach. If symptomatic hypoglycemia $(<40 \mathrm{mg} / \mathrm{ml})$ was combined with hyperinsulinism ( $>20 \mu \mathrm{U} / \mathrm{ml}$ ) insulinoma was confirmed by a supervised fasting test. A Vipoma was defined in case of watery diarrhea (>61/day) and elevated VIP serum levels $(>130$ $\mathrm{pg} / \mathrm{ml}$ ). Pancreatic tumors were considered non-functional if neither hormone levels were elevated nor symptoms associated with hormone excess were evident except PP. Tumors were classified as malignant if they demonstrated infiltrating growth, angioinvasion or lymph node or distant metastases. The pathological classification was performed according to Rindi and Klöppel [11].

The twenty fresh frozen tissue samples were obtained from the tumor bank of Philipps-University of Marburg. Clinical follow-up was conducted by the patients' personal physicians or at outpatient attendance. Survival was calculated as the time from surgical resection to either death or last follow up. Informed consent was ob- tained from all patients. The Ethics Committee of the University approved this study and all patients participating in the study consented to sampling.

Before proceeding with RNA isolation from these 20 tumor samples, an initial histochemical staining was performed to confirm a neoplastic cellularity of $85 \%$. Again, the reference contained pooled RNA from normal human islet cells.

\subsection{RNA Isolation and Quantitative Real-Time RT-PCR (qRT-PCR)}

Frozen control and tumor tissue samples were homogenized in the presence of guanidinium thiocyante-phenol-chloroform (Trizol Reagent; Invitrogen, Paisley, Scotland, UK) following the manufacturer's protocol. Total RNA was then further purified by digestion with DNaseI and recovery of RNA using an RNeasy kit (Qiagen, Hilden, Germany) according to the supplier's protocol. The relative expression of Noxa mRNA in tumors and normal islet cells was determined by Real Time PCR on a Roche Light Cycler using the following primers: NOXA_for GTC CGA GGT GCT CCA GTT; $N O X A \_$rev AAA CGT GCA CCT CCT GAG A (Amplicon 298 bp; Accession number NM 21127; 6) and GAPDH_for CGT CTT CAC CAC CAT GGA GA; GAPDH_rev CGG CCA TCA CGC CAC AGT TT as previously described [12]. Negative controls contained no cDNA. Expression levels were normalized to GAPDH.

\subsection{Cell Culture and Biological Reagents}

The BON-1 cell line was derived from a peripancreatic lymph node metastasis of a serotonin-producing PNEN [13]. The cells were cultured in a 1:1 mixture of Hams F12 Nutrient Mixture and 1x Dulbecco's Modification of Eagle's Medum (DMEM) (Life Technologies). The QGP-1 cell line was derived from a somatostatinoma and was grown in RPMI 1640. Both cell lines were supplemented with $10 \%$ fetal calf serum, 1\% L-glutamine (Biochrom KG, Berlin, Germany) and 1\% penicillinstreptomycin (Life technologies) and grown in an incubator maintaining an atmosphere of $95 \%$ humidity and $5 \% \mathrm{CO}_{2}$ at $37^{\circ} \mathrm{C}$.

Each cell line was plated on day minus 1 and incubated on day 1 with $150 \mathrm{nM}$ Bortezomib (LC Laboratories, Boston) or not for $16 \mathrm{~h}$. The control cells received vehicle, DMSO. Both floating and adherent cells were harvested and whole cell extracts were obtained using RIPA buffer.

\subsection{Western Blot}

For the Western blot, $30 \mu \mathrm{g}$ of total protein from cell 
lysates were analyzed by 17\% SDS-PAGE and blotted onto nitrocellulose membrane (Schleicher \& Schuell, Whatman GmbH, Dassel, Germany). Filters were blocked with 5\% nonfat dry milk in PBS and incubated overnight at $4^{\circ} \mathrm{C}$ with specific antibodies (Noxa: Imgenex, San Diego, California, 1:100; Cleaved Caspase 3, Cell Signaling Technology, 1:1000; Actin, Sigma-Aldrich, 1: 2500; c-Myc, Santa Cruz sc-42, 1:200). After washing, blots were incubated with horseradish peroxidase-conjugated secondary antibodies (Vectastain) and then revealed by enhanced chemiluminescence (Amersham Biosciences).

\subsection{Statistics}

Data were analyzed using SPSS, version 14.0 for Microsoft Windows. Means were compared using paired t-tests. A $p$-value $<0.05$ was considered significant.

\section{Results}

Based on previous results from our cDNA microarray analysis of 10 gastrinomas in comparison to pooled RNA from normal islet cells we proceeded to verify the finding of a downregulation of the Noxa gene in PNENs. For this purpose we selected 20 additional PNEN tumor samples.

\subsection{Patients}

The median age of patients (12 male and 8 female) was 44 years $(29-61)$ and these were followed for a median period of 61 months (13 - 193). The median tumor diameter was 15 mm (5 - 250). A summary appears in Table 1.

\subsection{PNENs vs. Normal Islet Cells}

Real time PCR analysis of 20 samples, 10 malignant and

Table 1. Summary of clinical data.

\begin{tabular}{|c|c|c|c|c|c|c|c|c|c|c|c|c|}
\hline $\begin{array}{l}\text { Pat } \\
\text { ID }\end{array}$ & $\begin{array}{c}\text { Spordic/MEN } \\
1\end{array}$ & Tumor & $\begin{array}{l}\text { Stage } \\
\text { WHO }\end{array}$ & $\begin{array}{l}\text { Age at } \\
\text { Dx (yr) }\end{array}$ & $\begin{array}{c}\text { Tumor } \\
\text { Size }(\mathbf{m m})\end{array}$ & LNM & $\begin{array}{l}\text { Liver } \\
\text { Met }\end{array}$ & Ki 67 & $\begin{array}{c}\text { Follow up } \\
\text { (mos) }\end{array}$ & Other therapies & $\mathrm{Ct}$ & Ct-Ref \\
\hline 1 & MEN1 & M GAS & III & 46 & 6 & $\mathrm{y}$ & $\mathrm{N}$ & $1 \%$ & NED (136) & none & 33.01 & 7.58 \\
\hline 2 & MEN1 & M GAS & III & 49 & 5 & $\mathrm{n}$ & $\mathrm{Y}$ & ND & DOC (84) & none & 32.9 & 7.47 \\
\hline 3 & MEN1 & M GAS & III & 35 & 8 & $\mathrm{y}$ & $\mathrm{N}$ & $2-3 \%$ & DOD (136) & DOTATOC & 31.09 & 5.66 \\
\hline 5 & MEN1 & NECA & III & 33 & 10 & $\mathrm{n}$ & $\mathrm{N}$ & $6 \%$ & AWD (120) & none & 32.81 & 7.38 \\
\hline 6 & sporadic & M GAS & III & 58 & 15 & $\mathrm{n}$ & $\mathrm{Y}$ & ND & DOD (78) & none & 30.51 & 5.08 \\
\hline 7 & sporadic & M GAS & III & 29 & 15 & $\mathrm{y}$ & $\mathrm{N}$ & $2 \%$ & NED (146) & none & 35.12 & 9.69 \\
\hline 8 & sporadic & M GAS & III & 50 & 20 & $\mathrm{n}$ & $\mathrm{N}$ & ND & NED (235) & none & 34.81 & 9.38 \\
\hline 9 & sporadic & NECA & III & 45 & 25 & $\mathrm{y}$ & $\mathrm{Y}$ & $30 \%$ & AWD (25) & somatosttin-LAR & 35.81 & 10.38 \\
\hline 10 & sporadic & NECA & III & 44 & 15 & $\mathrm{y}$ & $\mathrm{N}$ & $2 \%$ & AWD (18) & none & 33.1 & 7.67 \\
\hline 11 & MEN1 & INS & II & 48 & 40 & $\mathrm{n}$ & $\mathrm{N}$ & ND & NED (107) & none & 31.98 & 6.55 \\
\hline 12 & MEN1 & INS & I & 32 & 20 & $\mathrm{n}$ & $\mathrm{N}$ & $3 \%$ & NED (79) & none & 31.24 & 5.81 \\
\hline 13 & MEN1 & NFPET & I & 30 & 10 & $\mathrm{n}$ & $\mathrm{N}$ & $1 \%$ & AWD (72) & none & 29.79 & 4.36 \\
\hline 14 & MEN1 & NFPET & II & 54 & 50 & $\mathrm{n}$ & $\mathrm{N}$ & $2 \%$ & AWD (108) & none & 35.65 & 10.22 \\
\hline 15 & MEN1 & NFPET & II & 37 & 40 & $\mathrm{n}$ & $\mathrm{N}$ & $1 \%$ & NED (60) & none & 34.96 & 9.53 \\
\hline 16 & sporadic & GAS & II & 61 & 15 & $\mathrm{n}$ & $\mathrm{N}$ & ND & NED (125) & none & 30.73 & 5.3 \\
\hline 17 & sporadic & GAS & I & 45 & 9 & $\mathrm{n}$ & $\mathrm{N}$ & ND & DOD (124) & none & 31.2 & 5.77 \\
\hline 19 & sporadic & INS & II & 32 & 13 & $\mathrm{n}$ & $\mathrm{N}$ & $5 \%$ & NED (15) & none & 33.59 & 8.16 \\
\hline 20 & sporadic & INS & $\mathrm{I}$ & 32 & 8 & $\mathrm{n}$ & $\mathrm{N}$ & $2 \%$ & NED (52) & none & 27.44 & 2.01 \\
\hline
\end{tabular}

LNM, lymph node metastasis; Met, metastasis; M, malignant; Gas, gastrinoma; VIP, vipoma; NECA, neuroendocrine carcinoma; INS, insulinoma; NFPET, nonfunctional pancreatic endocrine tumor; NED, no evidence of disease; DOC, dead of unrelated causes; DOD, dead of disease; AWD, alive with disease; ND, not determined; y, yes; n, no; Ref, reference. 
10 benign, was performed to determine the expression of Noxa using normal human islet cells pooled from three patients as a reference. All values for Noxa were normalized according to the results with $G A P D H$. All samples tested demonstrated a decrease in the level of expression of Noxa. Figure 1 shows the results of this analysis where the average threshold cycle (Ct) is presented for the group of 20 PNENs $(\mathrm{Ct}=32.1)$ compared to that of normal islet cells $(\mathrm{Ct}=25.3)$. A paired t test of these results suggests that this result is very statistically significant $(\mathrm{p}=0.0036)$.

Of the 20 PNENs, 10 were from MEN1 patients: 5 malignant and 5 benign. Interestingly, there was no significant difference in the downregulation of Noxa between these two groups: MEN1 and non-MEN1 (data not shown).

\subsection{Malignant vs. Benign}

The results of the real time PCR analysis were graphed according to the designation malignant $(\mathrm{Ct}=33.05)$ or benign $(\mathrm{Ct}=31.21)$. Interestingly, here there is a statistically significant difference between the two groups as determined by a two tailed test $(\mathrm{p}=0.0385)$. The loss of Noxa expression is greater in malignant tumors as compared to benign tumors (Figure 1).

\subsection{PNENs Larger Than $20 \mathrm{~mm}$}

A further analysis compared the tumors $>20 \mathrm{~mm}$ in size to the expression in normal islet cells. Here the decrease in expression of the tumor suppressor, Noxa is most evident with an average Ct of 33.5. The statistical analysis results in a two-tailed $p$ value of less than 0.0001 which is extremely statistically significant (Figure 1).

Thus, the results of the initial microarray analysis were confirmed by real time PCR on 20 additional tumor samples.

\subsection{Noxa Expression in Tumor Cell Lines, QGP1 and BON1}

The neuroendocrine tumor cell lines, BON1 (serotoninproducing PNEN) and QGP1 (somatostatinoma) were analyzed for their expression of Noxa. For this purpose the cells were grown in culture and total protein extracts were prepared and applied to a 17\% SDS PAGE. The results of this Western blot analysis are presented in Figure 2. Lanes 1 and 3 contain the extracts from BON1 and QGP1 cells, respectively. Although the presence of Actin $(42 \mathrm{kDa})$ verifies the presence of protein in the lane, there is no band at $11 \mathrm{kDa}$ where Noxa protein would be expected to run. This lack of or very low level of expres- sion mimics the real time PCR results with the PNEN patient samples.

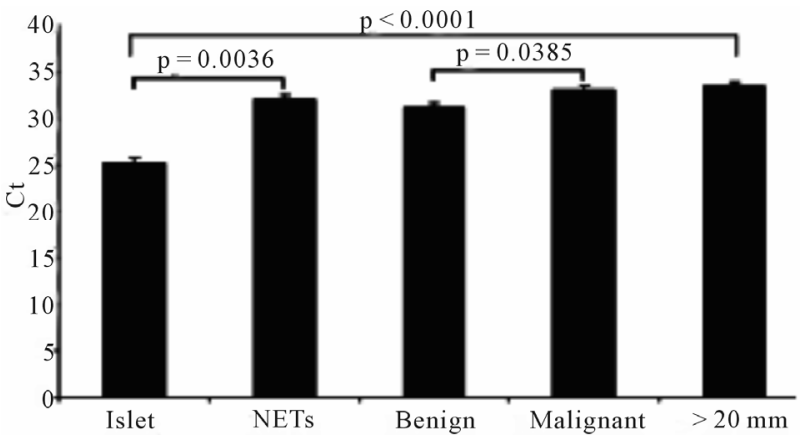

Figure 1. Results of the real time PCR Analyses for Noxa expression in PNENs.

\subsection{Expression of Noxa in Cell Lines Inducible by Bortezomib}

Both cell lines were treated with or without $150 \mathrm{nM}$ bortezomib for $16 \mathrm{~h}$. The cell cultures were analyzed micro scopically to confirm cell death in the treated cultures. Both floating and adherent cells were harvested, pelleted and RIPA buffer was used to isolate cellular protein. Following quantitation, $30 \mu \mathrm{g}$ were applied to the SDS PAGE, blotted and the membrane was hybridized with antibodies. As shown in Figure 2 Actin as a loading control was not changed by treatment with the drug. However, the level of expression of Noxa, which was not visible in untreated cells (lanes 1 and 3) was clearly induced following treatment with bortezomib (lanes 2 and 4).

Cleavage of Caspase 3 was observed following the treatment with the drug as evidence that the cell killing is apoptosis. The known function of Noxa as a pro-apoptotic member of the Bcl-2 family would suggest that the increased expression of this protein leads to the apoptotic death of the cells.

The level of expression of c-MYC was visible before treatment with the drug and was induced by treatment of the cells with bortezomib. As MYC is known to transcriptionally activate the expression of Noxa [14,15], this would be the proposed mechanism for the increased expression.

Thus, treatment with Bortezomib stabilizes MYC that re-induces Noxa expression in these cells, leading to apoptotic killing.

\section{Discussion}

In this study we have validated the down regulation of the pro-apoptotic Noxa gene in PNENs. These tumors express Noxa at a lower level than that of normal islet cells. Malignant tumors display a more significant decrease than benign and larger tumors $(>20 \mathrm{~mm})$ show the greatest decrease. This low level of expression is mirrored in the tumor cell lines, BON1 and QGP1. 

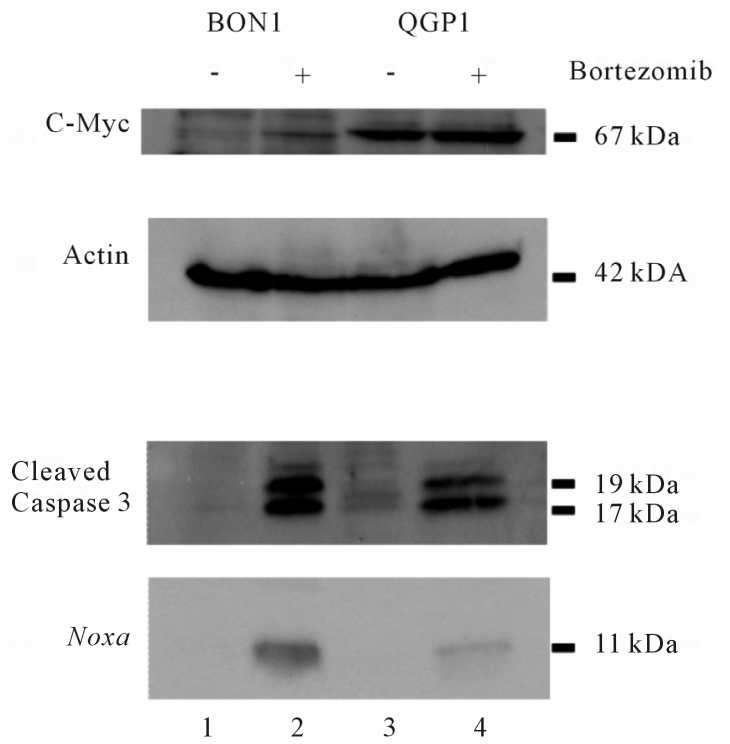

Figure 2. Western Blot Analysis of BON1 and QGP1 cells treated with and without bortezomib.

Bortezomib, also known as Velcade and previously known as PS-341, is a dipeptidyl borinic acid that is a specific, potent and reversible inhibitor of the $26 \mathrm{~S}$ proteosome. Many regulatory proteins governing the cell cycle, transcription factor activation, apoptosis and cell trafficking are the substrates for proteosome-mediated degradation. This proteosome inhibitor has shown antitumor activity in a wide range of malignancies $[7,8]$.

It has been previously shown that bortezomib promotes a proapoptoitc shift in the levels of proteins involved in mitochondrial outer-membrane permeabilization and is a potent activator of the mitochondrial pathway of apoptosis $[7,8,16]$. It induces the proapoptotic BH3-only family member Noxa in a p53 independent fashion that is a key element in the triggering of a caspase cascade culminating in apoptosis in melanoma and myeloma cells. The proteasome modulates not only the half-life of Noxa protein but also its mRNA levels [7,8] Noxa was identified as the first proapoptotic factor induced by bortezomib preferentially in cancer cells $[7,8$, 14]. Tumor cell-restricted induction of Noxa is a unique impact of bortezomib on the apopotoic machinery of tumor cells.

The protooncogene, c-MYC, itself is a proteasomal target whose levels of function are invariably upregulated during tumor progression. c-MYC is known to be overexpressed in PNENS $[17,18]$. The identification of conserved MYC binding sites in the Noxa promoter explains the mechanism of induction of Noxa expression following stabilization of MYC protein following proteasomal inhibition [14]. This regulation of the apoptotic machinery by c-MYC underscores a strategy to exploit the altered genetic background of tumor cells for a spe- cific induction of cell death. The function of c-MYC could be the long sought after oncogenic event conferring sensitivity of cancer cells to proteasome inhibition in contrast to healthy cells [14].

In the present study treatment with the proteosome inhibitor, bortezomib induces the protein level of c-MYC (Figure 2, lanes 2 and 4). C-MYC acts as an inducer of the expression of Noxa (Figure 2). The increased level of Noxa in neuroendocrine tumor cells leads to apoptosis as evidenced by the cleavage of Caspase-3 [19] (Figure 2). Although validation in animal studies should still be performed, these results support the use of proteasome inhibitors for the treatment of neuroendocrine tumors.

A common feature of PNENs is their slow-growing nature and a long standing question has been as to why these tumor entities, although slow growing, do not die. The present study describes a lesion in the apoptotic pathway that may be partially explained by the lack of Noxa expression. Although the mechanism leading to lower Noxa expression levels in these tumors relative islet cells is not yet known, this finding can be exploited in the treatment of these tumor entities. Proteasome inhibitors such as bortezomib can be used to re-induce this expression and lead to cell killing. In addition exploration into other drugs that exploit this pathway would be warranted to further the treatment of neuroendocrine tumor patients.

\section{Acknowledgements}

We express our appreciation to all patients who participated in the study. This research did not receive any specific grant from any funding agency in the public, commercial or not-for-profit sector.

\section{REFERENCES}

[1] B. Eriksson, K. Oberg and M. Stridsberg, "Tumor Markers in Neuroendocrine Tumors,” Digestion, Vol. 62, Suppl. 1, 2000, pp. 33-38. http://dx.doi.org/10.1159/000051853

[2] W.E. Schmidt, E.G. Siegel, H. Kratzin and W. Creutzfeldt W, "Isolation and Primary Structure of Tumor-Derived Peptides Related to Human Pancreastatin and Chomogranin A," Proceedings of the National Academy of Sciences of the United States, Vol. 85, No. 21, 1988, pp. 8231-8235. http://dx.doi.org/10.1073/pnas.85.21.8231

[3] E. Raymond, L. Dahan, J.-L. Raoul, Y.-J. Bang, I. Borbath, C. Lombard-Bohas, J. Valle, P. Metrakos, D. Smith, A. Vinik, J.-S. Chen, D. Hörsch, P. Hammel, B. Wiedenmann, E. Van Cutsem, S. Patyna, D.R. Lu, C. Blanckmeister, R. Chao and P. Ruszniewski, "Sunitinib Malate for the Treatment of Pancreatic Neuroendocrine Tumors," The New England Journal of Medicine, Vol. 364, 2011, pp. 501-513. http://dx.doi.org/10.1056/NEJMoa1003825

[4] J. C. Yao, M. H. Shah, T. Ito, C. L. Bohas, E. M. Wolin, 
E. Van Cutsem, T.J. Hobday, T. Okusaka, J. Capdevila, E. G. E. de Vries, P. Tomassetti, M. E. Pavel, S. Hoosen, T. Haas, J. Lincy, D. Lebwohl and K. Öberg, "Everolimus for Advanced Pancreatic Neuroendocrine Tumors," The New England Journal of Medicine, Vol. 364, 2011, pp. 514-523. http://dx.doi.org/10.1056/NEJMoa1009290

[5] G. Klöppel, P. A. Intveld, B. Stamm and P. U. Heitz, “The Endocrine Pancreas," In: K. Kovacs and S. L. Asa, Eds., Functional Endocrine Pathology, Blackwell Scientific Publications, Boston, 1990, pp. 396-421.

[6] T. Shibue, K. Takeda, E. Oda, H. Tanaka, H. Murasawa, A. Takaoka, Y. Morishita, S. Akira, T. Taniguchi and N. Tanaka, "Integral Role of Noxa in p53-Mediated Apoptotic Response," Genes \& Development, Vol. 17, 2003, pp. 2233-2238. http://dx.doi.org/10.1101/gad.1103603

[7] J.-Z. Qin, J. Ziffra, L. Stennett, B. Bodner, B. K. Bonish, V. Chaturvedi, F. Bennett, P. M. Pollock, J. M. Trent, M. J. C. Hendrix, P. Rizzo, L. Miele and B. J. Nickoloff, "Proteasome Inhibitors Trigger NOXA-Mediated Apoptosis in Melanoma and Myeloma Cells," Cancer Research, Vol. 65, 2005, pp. 6282-6293. http://dx.doi.org/10.1158/0008-5472.CAN-05-0676

[8] Y. Fernandez, M. Verhaegen, T. P. Miller, J. L. Rush, P. Steiner, A. W. Opipari, S. W. Lowe and M. S. Soengas, "Differential Regulation of Noxa in Normal Melanocytes and Melanoma Cells by Proteasome Inhibition: Therapeutic Implications," Cancer Research, Vol. 65, 2005, pp. 6294-6304. http://dx.doi.org/10.1158/0008-5472.CAN-05-0686

[9] E. P. Slater, V. Fendrich, J. Waldmann, E. Nalbatow, B. Chaloupka and D. K. Bartsch, "Down-regulation of the Noxa Gene in Gastrinomas,” Experimental and Clinical Endocrinology \& Diabetes, 2006.

[10] A. K. Jansson, A. M. Emterling, G. Arbman and X.-F. Sun, "Noxa in Colorectal Cancer: A Study on DNA, mRNA and Protein Expression,” Oncogene, Vol. 22, 2003, pp. 4675-4678. http://dx.doi.org/10.1038/sj.onc.1206655

[11] G. Rindi and G. Klöppel, "Endocrine Tumors of the Gut and Pancreas Tumor Biology and Classification,” Neuroendocrinology, Vol. 80, Suppl. 1, 2004, pp. 12-15. http://dx.doi.org/10.1159/000080733

[12] E. P. Slater, S. M. Diehl, P. Langer, B. Samans, A. Ramaswamy, A. Zielke and D. K. Bartsch, "Analysis by cDNA Microarrays of Gene Expression Patterns of Hu- man Adrenocortical Tumors," European Journal of Endocrinology, Vol. 154, 2006, pp. 587-598. http://dx.doi.org/10.1530/eje.1.02116

[13] B. M. Evers, J. Ishizuka, C. M. Townsend and J. C. Thompson, "The Human Carcinoid Cell Line, BON," Annals of the New York Academy of Sciences, Vol. 733, 1994, pp. 393-406. http://dx.doi.org/10.1111/j.1749-6632.1994.tb17289.x

[14] M. A. Nikiforov, M. Riblett, W. H. Tang, V. Gratchouck, D. Zhuang, Y. Fernandez, M. Verhaegen, S. Varambally, A. M. Chinnaiyan, A. J. Jakubowiak and M. S. Soengas, "Tumor Cell-Selective Regulation of NOXA by c-MYC in Response to Proteasome Inhibition," Proceedings of the National Academy of Sciences of the United States, Vol. 104, No. 9, 2007, pp. 19488-19493. http://dx.doi.org/10.1073/pnas.0708380104

[15] S. T. Nawrocki, J. S. Carew, K. H. Maclean, J. F. Courage, P. Huang, J. A. Houghton, J. L. Cleveland, F. J. Giles and D. J. McConkey, "Myc Regulates Aggresome Formation, the Induction of Noxa, and Apoptosis in Response to the Combination of Bortezomib and SAHA," Blood, Vol. 112, No. 7, 2008, pp. 2917-2926. http://dx.doi.org/10.1182/blood-2007-12-130823

[16] J. Voortman, A. Checinska, G. Giaccone, J. A. Rodriguez and F. A. E. Kruyt, "Bortezomib, but not Cisplatin, Induces Mitochondria-Dependent Apoptosis Accompanied by Up-Regulation of Noxa in the Non-Small Cell Lung Cancer Cell Line NCI-H460,” Molecular Cancer Therapeutics, Vol. 6, No. 3, 2007, pp. 1046-1053. http://dx.doi.org/10.1158/1535-7163.MCT-06-0577

[17] D. Lindberg, O. Hessman, G. Akerström and G. Westin, "Cyclin-Dependent Kinase 4 (CDK4) Expression in Pancreatic Endocrine Tumors,” Neuroendocrinology, Vol. 86, 2007, pp. 112-118. http://dx.doi.org/10.1159/000106762

[18] I. Arany, P. Rady, B. M. Evers, S. K. Tyring and C. M. Townsend, "Analysis of Multiple Molecular Changes in Human Endocrine Tumours,” Surgical Oncology, Vol. 3, No. 3, 1994, pp. 153-159. http://dx.doi.org/10.1016/0960-7404(94)90044-2

[19] D. E. Larsson, M. Wickström, S. Hassan, K. Oberg and D. Granberg, "The Cytotoxic Agents NSC-95397, Brefeldin A, Bortezomib and Sanguinarine Induce Apoptosis in Neuroendocrine Tumors in Vitro," Anticancer Research, Vol. 30, No. 1, 2010, pp. 149-156. 